NBER WORKING PAPERS SERIES

OPTIMAL INVESTMENT STRATEGIES FOR UNIVERSITY ENDOWMENT FUNDS

Robert C. Merton

Working Paper No. 3820

NATIONAL BUREAU OF ECONOMIC RESEARCH

1050 Massachusetts Avenue

Cambridge, MA 02138

August 1991

Robert C. Merton is George Fisher Baker Professor of Business Administration at Harvard University and a research associate of the National Bureau of Economic Research. This paper is part of NBER's research program in Financial Markets and Monetary Economics. Any opinions expressed are those of the author and not those of the National Bureau of Economic Research. 
NBER Working Paper \#3820

August 1991

OPTIMAL INVESTMENT STRATEGIES FOR UNIVERSITY ENDOWMENT FUNDS

\section{ABSTRACT}

A common approach to the management of endowment is to treat it as if it were the only asset of the university. This approach leads to prescriptions for optimal investment and expenditure policies that are essentially the same across universities. Indeed, the resulting optimal portfolio strategies are focused almost exclusively on providing an efficient tradeoff between risk and expected return, a generic objective that is just as applicable to individuals and non-academic institutions as it is to universities. In contrast, the model developed here provides intertemporally optimal investment and expenditure rules for endowment that take account of the university's overall objectives and total resources. The explicit inclusion of other university assets in addition to endowment leads to optimal endowment portfolios that are not efficient in the sense of the risk-return tradeoff. Moreover, two universities with similar objectives and endowments can have very different optimal portfolios and expenditure patterns if their non-endowment sources of cash flow are different. The model also takes account of the uncertainty surrounding the costs of the various activities such as education, research, and knowledge storage that define the purpose of the university. As a result, the analysis reveals a perhaps somewhat latent role for endowment: namely, hedging against unanticipated changes in those costs.

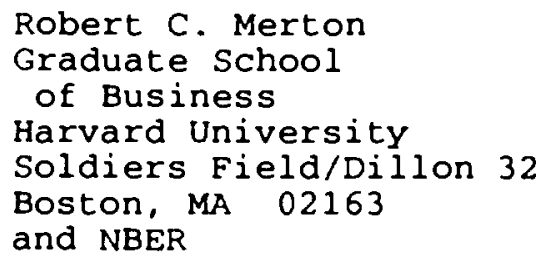




\title{
OPTIMAL INVESTMENT STAATEGIES FOR UNIVERSITY ENDOWMENT FUNDS
}

\author{
Robert C. Merton
}

\section{Introduction}

To examine the question of optimal investment strategies for university endownent funds, one must, of course, address the issue of the objective function by which optimelity is to be measured. My impression is that practicing money managers essentially side-step the issue by focusing on generically efficient risk-return objective functions for investment which are just as applicable to individuals or non-academic institutions as they are to universities. Perhaps the most comon objective of this type is mean-variance efficiency for the portfolio's allocations. Black (1976) provides a deeper approach along those lines that takes account of tax and other institutional factors including certain types of non-endowment assets held by institutions. The Ford Foundation study of 1969 gave some early practical (if ex-post. somewhat untimely) guidance for investment allocations.

Much of the academic literature (which is not copious) seems to focus on appropriate spending policy for endowment, taking as given that the objective for endowment is to provide a perpetual level flow of expected real income (cf. Eisner (1974), Litvack, Malkiel, and Quandt (1974), Nichols (1974), and Tobin (1974)). Ennis and Williamson (1976) present a history of spending patterns by universities and a discussion of various spending rules adopted. They also discuss the interaction between spending and investment policies. 
Fama and Jensen (1985) discuss the role of non-profit institutions as part of a general analysis of organizational forms and investment objective functions, but they do not address the functions of endowment in such institutions.

In contrast, Hansmann (1990) provides a focused and comprehensive review of the various possible roles for a university's endowment. Despite the broad coverage of possibilities ranging from tax incentives to promoting intergenerational equity, he is unable to find compelling empirical evidence to support any particular combination of objectives. Indeed, he concludes that ...prevailing endownent spending rules seem inconsistent with most of these objectives" (p.39). Hansmann goes on to assert (p.39-40):

"It appears, however, that surprisingly little thought has been devoted to the purposes for which endowments are maintained and that, as a consequence, their rate of accumulation and the pattern of spending from their income have been managed without much attention to the ultimate objectives of the institutions that hold them."

The course taken here to address this question is in the middle range: It does not attempt to specify in detail the objective function for the university, but it does derive optimal investment and expenditure policy for endownent in a context which takes account of overall university objectives and the availability of other sources of revenue besides endowment. In that respect, it follows along lines similar to the discussion in Black $(1976,26-8)$. In addition, our model takes explicit account of the uncertainties surrounding the costs of university activities. As a result, the analysis reveals another (perhaps somewhat latent) purpose for endowment: namely, hedging against unanticipated changes in those costs. Formal trading rules for implementing this hedging function are derived. However, the paper neither assesses which 
costs, as an empirical matter, are more tmportant to hedge nor does 1 examine the feasibility of hedging those costs using available traded securities. The Interested reader should see Brinkman (1981,1990). Brovender (1974), Nordhaus (1989), and Snyder (1988) where the various costs of universities are described and modelled, both historlcally and prospectively.

Grinold. Hopklns, and Massy (1978) develop a budget-planning model which also Integrates endowment returns with other revenue and expense flows of the university. However, their model differs significantly from the one presented here, perhaps because their focus is on developing policy guldelines for expenditures instead of optimal intertemporal management of endowment.

The mathematical model for optimal expenditures and investment is developed in Sections 2 and 3 . It is based on a standard intertemporal consumption and portfolio-selection model. Hence, the formal structure of the optimal demand functions is already widely studied in the literature. It 1s the application of this model to the management of university endowment which is new. For analytical simplicity and clarity, the model is formulated in continuous time. However, it is evident from the work of constantinides (1989), Long (1974), and Merton (1977) that a discrete-time version of the model would produce similar results. The reader who prefers to be exposed to the basic insights provided by the model before going through the detailed mathematical analysis should begin with the summary and conclusions discussion in Section 4 . 


\section{The Model}

The functions or purposes of the university are assumed to be a collection of activities or outputs such as education, training, research, and storage of knowledge. We further assume that the intensities of those activities can be quantified and there exists a preference ordering for ranking alternative intertemporal programs. In particular, the criterion function for this ranking can be written as:

$$
\max E_{0}\left\{\int_{0}^{\infty} \bar{U}\left[Q_{1}, \ldots, Q_{m}, t\right] d t\right\} \text {, }
$$

where $Q_{f}(t)$ denotes the quantity of activity $j$ per unit time undertaken at time $t, j=1, \ldots, m$; the preference function $\bar{U}$ is assumed to be strictly concave in $\left(Q_{1}, \ldots, Q_{ \pm}\right)$; and $E_{\tau}$ denotes the expectation operator, conditional on knowing all relevant information as of time $t$. This preference ordering satisfies the classic von Neumann-Morgenstern axioms of choice, exhibits positive risk aversion, and includes "survival" (of the institution) as a possible objective. The infinite time horizon structure in (1) implies only that there need not be a definite date when the university will liquidate. As shown in Merton (1990a, 149-51,609-11), Ū can reflect the mortality characteristics of an uncertain liquidation date.

The intertemporally additive and independent preference structure in (1) can be generalized to include non-additivity, habit-formation and other pathdependent effects on preferences, along the lines of Bergman (1985), Constantinides (1990), Detemple and Zapatero (1989), Duffie and Epstein (1989), Hindy and Huang (1989), Sundaresan (1989), and Svensson (1989). 
However, as shown in Merton (1990a, 207-9), those more-realistic preference functions do not materially affect the optimal portfolio demand functions. Moreover. just as Grossman and Laroque (1990) show for transactions costs in consumption, so it can be shown here that imposing adjustment costs for changing the levels of university activities does not alter the structure of the portfolio demand functions. Hence, because the focus of the paper is on optimal investment (rather than optimal expenditure) strategies, we assume no adjustment costs for activities and retain the additive independent preference specification to provide analytical simplicity.

Let $S_{j}(t)$ denote the (net) cost to the university of providing one unit of activity $j$ at time $t, j=1, \ldots \ldots$. For example, if $j-1$ denotes the activity of having full-tuition-paying undergraduates, then $S_{1}$ would be the unit cost of providing the education minus the tuition received. If $j=2$ denotes the activity of having undergraduates who receive financial aid, the unit cost $S_{2}$ would equal $S_{1}$ plus the financial aid given. In general, all costs and receipts such as tuition that are directly linked to the quantities of specific activities undertaken are put into the activity costs or prices, $\left\{S_{j}\right\}$. As will be described, fixed costs and sources of positive cash flows to the university that do not depend directly on the activity quantities are handled separately. As in Merton (1990a, 202, 499). we assume that the dynamics for these costs are described by the stochastic differential equations: for $s=\left(S_{1}, \ldots, s_{a}\right)$,

$$
d S_{j}=f_{j}(S, t) S_{j} d t+g_{j}(S, t) S_{j} d q_{j}, \quad j=1 \ldots m
$$


where $f_{f}$ is the instantaneous expected rate of growth in $s_{j}, g_{j}$ is the instantaneous standard deviation of the growth race, and $\mathrm{dq}_{j}$ is a wiener process with the instantaneous correlation coefficient between $d q_{i}$ and $d q_{j}$ given by $v_{i j}, i, j=1, \ldots, m$. $f_{j}$ and $g_{j}$ are such that $d s_{j} \geq 0$ for $S_{j}=0$ which ensures that $S_{j}(t) \geq 0$. Especially since (S) has components that depend on tuition. financial aid and other variables over which the university has some control, one would expect that the dynamic path for those costs would be at least partially endogenous and controllable by the university, even though competition among universities would limit the degree of controllability. However, as specified, (2) is an exogenous process, not controlled by the university. Alternatively, it can be viewed as the "reducedform" process for $S$ after optimization over non-portfolio choice variables. The university is assumed to have $\mathrm{N}$ non-endowment sources of cash flows which we denote by $Y_{k}(t) d t$ for the $k^{\text {th }}$ source at $t$ ime $t$. Examples of such sources are gifts, bequests, university business income, and public and private-sector grants. It can also be used to capture transfer-pricing for the use of buildings and other university-specific assets where $Y_{k}$ is the rental rate and this rental fee appears as an offsetting charge in the $\left\{s_{j}\right\}$ for the appropriate university activities. The dynamics for these cash flows are modeled by: for $Y=\left(Y_{1}, \ldots, Y_{N}\right)$,

$$
d Y_{k}=\mu_{k}(Y, S, t) Y_{k} d t+\delta_{k}(Y, S, t) Y_{k} d \varepsilon_{k}
$$

where $\mu_{k}$ and $\delta_{k}$ depend at most on the current levels of the cash flows and the unit costs of university activities and $d \varepsilon_{k}$ is a Wiener process, 
$k=1, \ldots . N$. Equation (3) can also be used to take account of fixed costs or liabilities of the university such as faculty tenure commitments. by letting $Y_{k}<0$ to reflect a cash outflow. However, the focus here is on assets only and therefore, we assume that $\mu_{k}$ and $\delta_{k}$ are such that $d Y_{k} 20$ for $Y_{k}=0$ which implies that $Y_{k}(t) \geq 0$ for all $t$.

By inspection of (2) and (3), the dynamics for (Y,S) are jointly Markov. A more realistic model would have $\mu_{k}$ and $\delta_{k}$ depend on both current and historical values of $Q_{1} \ldots, Q_{a}$. For example, if a university has undertaken large amounts of research activities in the past, it may atract more grants and gifts in the future. The university may also affect the future expected cash flows from non-endowment sources by investing now in building up those sources. Thus, the dynamic process for $Y$ should be in part controllable by the university. However, again for analytical simplicity, the $Y$ process is taken as exogenous, because that abstraction does not significantly alter the optimal portfolio demand functions.

If for $k=1, \ldots, N, V_{k}(t)$ denotes the capitalized value at time $t$ of the stream of future cash flows, $Y_{k}(\tau)$ for $T \geq t$, and if $K(t)$ denotes the value of the endowment at time $t$, then the net worth or wealth of the university, $W(t)$ is given by

$$
W(t)=K(t)+\Sigma_{l}^{N} V_{k}(t)
$$

A model for determining the $V_{k}(t)$ from the posited cash flow dynamics in (3) is developed in Section 3 .

The endownent of the university is assumed to be invested in traded 
assets. There are $n$ risky assets and a riskless asset. If $P_{j}(t)$ denotes the price of the $j^{\text {th }}$ risky asset at time $t$. then the return dynamics for the risky assets are given by, for $j=1, \ldots, n$,

$$
d P_{j}=\alpha_{j} P_{j} d t+\sigma_{j} P_{j} d Z_{j}
$$

where $\alpha_{j}$ is the instantaneous expected return on asset j; of is the instantaneous standard deviation of the return; and $d Z_{j} i s$ a Wiener process. The instantaneous correlation coefficients $\left\{\rho_{1 j}, \eta_{k j}, \zeta_{1 j}\right\}$ are defined by, for $j=1, \ldots, n$,

$$
\begin{array}{ll}
d z_{1} d Z_{j}=p_{i j} d t & , \quad i=1, \ldots, n \\
d q_{k} d Z_{j}=\eta_{k j} d t & k=1, \ldots, m \\
d e_{1} d z_{j}=\zeta_{1 j} d t, & 1=1, \ldots, N
\end{array}
$$

For computational simplicity and to better isolate the special characteristics of endowment management from general portfolio management, we simplify the return dynamics specification and assume that $\left\{\alpha_{j}, \sigma_{j}, p_{1 j}\right\}$ are constants over time, $i, j=1, \ldots, n$. As shown in Merton (1990a, Chs. 4, 5, and 6), this assumption of a constant investment opportunity set implies that $\left\{P_{j}(t+\tau) / P_{j}(t)\right\}, j=1, \ldots, n$, for $t>0$ are jointly lognormally distributed. The riskless asset earns the interest rate $r$ which is also constant over time. Optimal portfolio selection for general return dynamics would follow along the lines of Merton (1990a, Chs. 5, 15, 16; 1990b, Sec. 7). To analyze the optimal intertemporal expenditure and portfolio-selection problem for the university, we begin with a further simplified version of the 
model in which the university's entire net worth is endowment [i.e., $Y_{k}(t)$ $v_{k}(t)=0, k=1, \ldots, N$ and $\left.W(t)=K(t)\right]$. The budget-equation dynamics for $W(t)$ is then given by, $d W=\left[\left(\Sigma^{n} w_{j}(t)\left(\alpha_{j}-r\right)+r\right) W-\Sigma_{1} m Q_{k} S_{k}\right] d t+\Sigma_{1}^{n} w_{j}(t) W \sigma_{j} d Z_{j}$

where $w_{j}(t)=$ the fraction of the university's wealth allocated to risky

asset $j$ at time $t, j=1, \ldots, n$; the fraction allocated to the riskless asset is thus $1-\Sigma_{1}{ }^{n} w_{j}$. Trustees, donors, and the government are assumed not to impose explicit limitations on investment policy for the endownent. other than general considerations of prudence. In particular, borrowing and short-selling are permitted and so the choice for $\left\{w_{j}\right\}$ is unrestricted. We further posit that spending out of endowment is not restricted, either with respect to overall expenditure or with respect to the specific activities on which it is spent. However, we do impose the feasibility restrictions that total expenditure at time $t, \Sigma_{1} Q_{k} S_{k}$. must be nonnegative and zero wealth is an absorbing state (i.e., $W(t)=0$ implies $W(t+T)=0$ for $T>0$ ).

At each time $t$, the university chooses a quantity of activities $\left\{Q_{1}, \ldots, Q_{m}\right\}$ and a portfolio allocation of its wealth so as to maximize lifetime utility of the university as specified in (1). Just as for the case of multiple consumption goods analyzed in Breeden (1979). Fischer (1975), and Merton (1990a, 205), so the solution for the optimal program here can be decomposed into two parts. First, at each $t$, solve for the utility-maximizing quantities of individual activities, $\left\{Q_{1}, \ldots, Q_{m}\right\}$, subject to an overall expenditure constraint, $C(t)=\Sigma_{1} Q_{k}(t) S_{k}(t)$. Second, solve for the optimal 
level of overall expenditures at $t$ ime $t$ and the optimal portfolio allocation of endowment.

The first part is essentially the static activity-choice problem under uncertainty

$$
\max _{\left\{Q_{1} \ldots Q_{m}\right\}} \bar{U}\left[Q_{1} \ldots, Q_{m}, t\right]
$$

subject to $C(t)=\Sigma_{1}{ }^{m} Q_{k} S_{k}(t)$. The first-order conditions for the optimal activity bundle $\left(Q_{1}{ }^{*} \ldots, Q_{m}^{*}\right)$ are given by: for $S_{k}(t)=S_{k}$.

$$
\bar{u}_{k}\left[Q_{1}^{*} \ldots Q_{m}^{\star}, t\right] / s_{k}=\tilde{U}_{j}\left[Q_{1}^{*}, \ldots, Q_{m}^{\star}, t\right] / s_{j} \quad k, j=1, \ldots, m
$$

with $C(t)=\Sigma_{1}{ }^{*} Q_{k}{ }^{*} S_{k}$. where subscripts on $\bar{U}$ denote partial derivatives (i.e.. $\bar{U}_{k}=\partial \bar{U} / \partial Q_{k}$ ). It follows from (8) that the optimal quantities can be written as $Q_{k}^{*}=Q_{k}^{*}[C(t), S(t), t], k=1, \ldots, m$.

Define the indirect utility function $U$ by $U[C(t), S(t), t] \equiv$ $\overline{\mathrm{U}}\left[Q_{1}^{*}, \ldots Q_{m}^{*}, t\right]$. By substituting $U$ for $\bar{U}$, we can rewrite (1) as:

$$
\max E_{0}\left\{\int_{0}^{\infty} U[C(t), S(t), t] d t\right\}
$$

where the "max" in (9) is over the intertemporal expenditure path $\{C(t)\}$ and portfolio allocations $\left\{w_{j}(t)\right\}$. Thus, the original optimization problem is transformed into a single-expenditure choice problem with "state-dependent" utility (where the "states" are the relative costs or prices of the various 
activities). Once the optimal total expenditure rules, $(C \star(t)\}$, are determined, the optimal expenditures on individual activities are determined by ( 8 ) with $C^{*}(t)=\Sigma_{1}=Q_{k}^{*} S_{k}$.

The solution of (9) follows by applying stochastic dynamic programming a in Merton (1990a, Chs. 4, 5, and 6). Define the Bellman or derived-utility function $\mathrm{J}$ by

$$
J[W, S, t]=\max E_{c}\left(I_{i} \cdot U[C(\tau), S(\tau), \tau] d \tau\right\}
$$

conditional on $W(t)=W$ and $S(t)=S$. From Merton (1990a, 181, 202; $1990 b$. 555), J will satisfy:

$$
\begin{aligned}
& 0=\max _{\{C, w\}} \mid U[C, S, t]+\lambda C+J_{t}+J_{W}\left\{\left(\Sigma_{1}^{n} w_{j}\left(\alpha_{j}-r\right)+r\right) W-C \mid\right. \\
& +\Sigma_{1}^{m} J_{i} f_{i} s_{i}+\frac{1}{2} J_{w w} \Sigma_{1}^{n_{1}} \Sigma_{1}^{n} w_{i} w_{j} \sigma_{i j} w^{2} \\
& \left.+\Sigma_{1}^{m_{1} n} J_{i W} w_{j} g_{i} s_{i} \sigma_{j} \eta_{i j}+\frac{1}{2} \Sigma_{1}^{m_{1} m} J_{i j} g_{i} s_{i} g_{j} s_{j}{ }_{i j}\right)
\end{aligned}
$$

subject to $J(0, S, t)=1_{t}^{\infty} \bar{U}[0, \ldots, 0, \tau] d \tau$, where subscripts on $J$ denote partial derivatives with respect to $W, t$, and $s_{i}, i=1, \ldots m$ and $\sigma_{1 j}=\rho_{1 j} \sigma_{1} \sigma_{j}$, the instantaneous covariance between the return on security i and $j . \lambda$ is a Kuhn-Tucker multiplier reflecting the non-negativity constraint on $C$ and at the optimum, it will satisfy $\lambda^{*} C^{*}=0$. The first-order conditions derived from (10) are:

$$
0=U_{C}\left[C^{*}, s, t\right]+\lambda * J_{w}(W, S, t)
$$

and 
where $C^{*}-C^{*}(W, S, t)$ and $w_{1}^{*}=w_{1}^{*}(W, S, t)$ are the optimal expenditure and portfolio rules expressed as functions of the state variables and subscripts on $U$ denote partial derivatives.

From (11a), the optimal expenditure rule is given by:

$$
\begin{gathered}
U_{C}\left[C^{*}, S, t\right]-J_{W}(W, S, t) \quad \text { for } C^{*}>0 \\
\lambda^{*}=\max \left\{0, J_{W}(W, S, t)-U_{C}[0, S, t]\right\}
\end{gathered}
$$

From (11b), the optimal portfolio allocation can be wrttten as:

$$
w_{1}{ }^{\star W}=A b_{i}+\Sigma_{1} \equiv H_{k} h_{k 1}, \quad i=1, \ldots, n
$$

where $b_{i}=\Sigma_{1}^{n} v_{1 j}\left(\alpha_{j}-\tau\right) ; h_{k i}=\Sigma_{1}^{n} \sigma_{j} g_{k} s_{k} \eta_{k j} v_{1 j} ; v_{1 j}$ is the $i j-e l e m e n t$ of the inverse of the instantaneous variance-covariance matrix of returns [ $\left.\sigma_{i j}\right]$; $A=-J_{H} / J_{W W}$ (the reciprocal of absolute risk aversion of the derived-utility function); and $H_{k} \equiv-J_{k H} / J_{W W}, k=1, \ldots, m$. $A$ and $H_{k}$ depend on the individual university's intertemporal preferences for expenditures and its current net worth. However, $b_{1}$ and $h_{k j}$ are determined entirely by the dynamic structures for the asset price returns and the unit costs of the various activities undertaken by universities. Hence, those parameters are the same for all universities, independent of their preferences or endowment size. To provide some economic intuition about the optimal allocation of endowment in (13), consider as a frame of reference the "standard" intertemporal portfolio selection problem with state-independent utility, $U=U(C(t)$, 
t). As shown in Merton (1990a, 131-6), given the posited return dynamics in (5). all such investors will hold instantaneously mean-variance efficient portfolios as their optimal portfolios. For $\partial U / \partial S_{k}=U_{k}=0, H_{k}=0, k=$ $1, \ldots . m$. Hence, in this case. (13) becomes $w_{1}{ }^{*} W=A b_{1}$, and $w_{1}{ }^{*} W / w_{1}{ }^{*} W=b_{1} / b_{1}$, the same for all investors. This is the well-known result that the relative holdings of risky assets are the same for all mean-variance efficient portfo1108. However, the state-dependent preferences for universities induced by the uncertainty surrounding the relative costs of undertaking different desired activities causes the more complex demand structure in (13).

To better understand this differential demand, $W_{1}{ }^{*} W-A b_{i}=\Sigma_{1}=H_{k} h_{k s}$. it is useful to examine the special case where, for each cost $S_{k}$, there exists an asset whose instantaneous return is perfectly correleted with changes in $S_{k}$. By renumbering securities if necessary. choose the convention that $n_{k k}=1$ in $(5 a), k=1, \ldots, m(m<n)$. As shown in Merton (1990a, 203-4). 1t follows that in this case, $h_{k k}=8_{k} s_{k} / \sigma_{k}$ for $k=1 \ldots, m$ and $h_{k j}=0$ for $k$ * j. Hence, we can rewrite (13) as:

$$
\begin{array}{rlrl}
w_{i}{ }^{*} W & =A b_{1}+H_{1} g_{i} s_{i} / \sigma_{i} & i & =1, \ldots m \\
& =A b_{i} & i & =m+1, \ldots n .
\end{array}
$$

By the strict concavity of $U$ with respect to $C, J$ is strictly concave in W. Hence, $J_{W U}<0$ and $H_{i}=-J_{L W} / J_{W M}$ is positively proportional to $J_{1 H}$. Thus, relative to a "normal" investor with state-independent preferences (i.e., $\left.H_{i}=0 . i-1, \ldots m\right)$. but the same current level of absolute risk aversion (i.e., $-J_{W H} / J_{H}$ ), the university will optimally hold more of asset i 
if $J_{i W}>0$ and less if $J_{1 H}<0,1=1, \ldots m$.

If $J_{1 H}>0$, then, at least locally, the university's marginal utility (or "need") for wealth or endowment becomes larger if the cost of undertaking activity 1 increases and it becomes smaller if this cost decreases. Because the return on asset $i$ is perfectly positively correlated with the cost of activity $i$, a greater-than-expected increase in $s_{1}$ will coincide with a greater-than-expected return on asset 1 . By holding more of asset 1 than a "normal" investor. the university thus assures itself of a relatively larger endowment in the event that $S_{i}$ increases and the need for wealth becomes more important. The university, of course, pays for this by accepting a relatively smaller endowment in the event that $s_{1}$ decreases and wealth is less important. The behavioral description for $J_{1 H}<0$ is just the reverse, because the need for endowment decreases if the cost of activity $i$ increases.

To perhaps help in developing further insights, we use (12) to interpret the differential demand component in (14) in terms of the indirect utility and optimal expenditure functions. By differentiating (12), we have that for $C^{*}(W, S, t)>0$,

$$
\begin{aligned}
& J_{W W}=U_{C C}\left[C^{*}, s, t\right] \frac{\partial C^{\star}}{\partial W} \\
& J_{k W}=U_{C C}\left[C^{\star}, s, t\right] \frac{\partial C^{*}}{\partial S_{k}}+U_{C k}\left[C^{\star}, s, t\right] \\
& A=-U_{C}\left[C^{*}, s, t\right] / / U_{C C}\left[C^{*}, s, t\right] \frac{\partial C^{*}}{\partial W} \\
& \left.H_{k}=-\mid \frac{\partial C^{\star}}{\partial S_{k}} / \frac{\partial C^{\star}}{\partial W}\right]+U_{C k}\left[C^{*}, s, t\right] /\left(-U_{C C}\left[C^{*}, s, t\right] \frac{\partial C^{\star}}{\partial W}\right)
\end{aligned}
$$


for $k-1, \ldots, m$. Because $U_{c c}<0$ and $\partial c^{*} / \partial W>0$ for $c^{*}>0$, we see that the sign of $H_{k}$ is determined by the impact of a change in the cost of activity $k$ on two items: the optimal level of total current expenditure and the marginal utility of expenditure. So, for example, if an increase in $s_{k}$ would cause both a decrease in optimal expenditure $\left(\partial C^{*} / \partial S_{k}<0\right)$ and an increase in the marginal utility of expenditure $\left(U_{C k}>0\right)$, then from (15). $H_{k}>0$ and the university will optimally hold more of asset $k$ than the corresponding investor with a mean-variance efficient portfolio.

Following (14) causes the university's optimal portfolio to be meanvariance inefficient and therefore, the return on the endowment will have greater volatility than other feasible portfolios with the same expected return. However, the value of the endowment or net worth of the university is not the "end" objective. Instead, it is the "means" by which the ends of a preferred expenditure policy can be implemented. Viewed in terms of the volatility of the time path of expenditure (or more precisely. the marginal utility of expenditure), the optimal strategy given in (14) is mean-variance efficient [cf. Breeden (1979) and Merton (1990a, 487-8)]. That is, because $\partial C^{*} / \partial W>0$, the additional increment in wealth that, by portfolio construction, occurs precisely when $S_{k}$ increases will tend to offset the negative impact on $C^{*}$ caused by that increase. There is thus a dampening of the unanticipated fluctuations in expenditure over time. In sum, we see that in addition to investing in assets to achieve an efficient risk-return tradeoff in wealth, universities should optimally use their endowment to hedge against unanticipated and unfavorable changes in the costs of the various activities 
in wealth, universities should optimally use their endowment to hedge against unanticlpated and unfavorable changes in the costs of the various activities that enter into their direct utility functions.

In closing this section, we note that the interpretation of the demand functions in the general case of (13) follows along the same lines as for the special case of perfect correlation leading to (14). As shown for the general case in Merton (1990a, 501-2: 1990b, 558-9), the differential demands for assets reflect attempts to create portfolios with the maximal feasible correlations between their returns and unanticipated changes in the $s_{k}$, $k=$ 1....m. These maximally-correlated portfolios perform the same hedging function as assets $1, \ldots m$ in the limiting case of perfect correlation analyzed in (14). Furthermore, if other state variables besides the various activities' costs (e.g. changes in the investment opportunity set) enter a university's derived utility function, then a similar structure of differential asset demands to hedge against the unanticipated changes in these variables will also obtain. 


\section{Optimal Endowment Management with Other Sources of Income}

In the previous section, we identified hedging of the costs of university activities as a reason for optimally deviating from "efficlent" portfolio allocations when endowment is the only means for financing those activities. In this section, we extend the analysis to allow other sources of cash flow to support the activities. To simplify the analysis, we make two additional assumptions: first, we posit that $\mu_{k}$ and $\delta_{k}$ in (3) are constants, which implies that $Y_{k}(t) / Y_{k}(0)$ is $l o g$-normally distributed, $k-1, \ldots N$. Second, we assume that for each $k$, there exists a traded security whose return is instantaneously perfectly correlated with the unanticipated change in $Y_{k}$. $k=1 \ldots, N$. By renumbering if necessary, we use the convention that traded security $k$ is instantaneously perfectly correlated with $Y_{k}$. Hence, it follows that $\zeta_{k k}-1$ in $(5 a)$ and.

$$
d \varepsilon_{k}=d z_{k}, k=1, \ldots N \quad \text {. }
$$

These two assumptions permit us to derive a closed-form solution for the capitalized values of the cash flows, $\left\{V_{k}(t)\right\}$, using contingent-claims analysis. As will be shown, those valuation functions are independent of the university's preferences or wealth level.

From (3), (5), and (16) with $\mu_{k}$ and $\delta_{k}$ constant, we have that the cash flows can be written as a function of the traded asset prices as follows, for $k=1, \ldots, N$,

$$
\left.\left.Y_{k}(t)-Y_{k}(0) \exp \mid-\phi_{k} t\right] \mid P_{k}(t) / P_{k}(0)\right)^{\beta_{k}}
$$


where $\phi_{k}=\beta_{k}\left(\alpha_{k}-\sigma_{k}{ }^{2} / 2\right)-\left(\mu_{k}-\delta_{k}{ }^{2} / 2\right)$ and $\beta_{k}=\delta_{k} / \sigma_{k}$. That (17) obtains can be checked by applying Ito's Lemma. We now derive the capitalized value for $Y_{k}$ following Merton (1990a, 415-9; 1990b, 562-3).

Let $F^{k}\left[P_{k}, t\right]$ be the solution to the partial differential equation. for $0 \leq t \leq T_{k}$.

$$
0=1 / 2 \sigma_{k}^{2} P_{k}^{2} F_{1}{ }^{k}+r P_{k} F_{1}^{k}-r F^{k}+F_{2}^{k}+Y_{k}
$$

subject to the boundary conditions

$$
\begin{aligned}
& F^{k}[0, t]=0 \\
& F^{k} /\left(P_{k}\right)_{k}^{\beta} \text { bounded as } P_{k} \rightarrow \infty \\
& F^{k}\left[P_{k}, T_{k}\right]=0
\end{aligned}
$$

where subscripts on $F^{k}$ in (18) denote partial derivatives with respect to its arguments $P_{k}$ and $t ; Y_{k}$ is given by (17); and $T_{k}$ is the last date at which the university receives the cash flows from source $k, k=1, \ldots, N$. It is a mathematical result that a solution exists to (18) - (19) and that it is unique. Moreover, for $Y_{k} \geq 0, F^{k} \geq 0$ for all $P_{k}$ and $t$. Consider a dynamic portfolio strategy in which $F_{l}^{k}\left[P_{k}(t), t\right] P_{k}(t)$ is allocated to traded asset $k$ at time $t$ and $V(t)-F_{1}{ }^{k}\left[P_{k}(t), t\right] P_{k}(t)$ is allocated to the riskless asset, where $V(t)$ is the value of the portfolio at 
time $t$. Furthermore, let the portfolio distribute cash (by selling securities if necessary) according to the flow-rate rule

$$
D_{2}\left[P_{k}, t\right]=Y_{k}(t)
$$

as given by (17). Then the dynamics of the portfolio can be written as, for $P_{k}(t)=P_{k}$ and $V(t)=V$.

$$
d V=F_{1}^{k}\left[P_{k}, t\right] d P_{k}+\left(\left[V-F_{1}^{k}\left[P_{k}, t\right] P_{k}\right] r-D_{2}\left[P_{k}, t\right]\right) d t .
$$

Since $F^{k}$ satisfies ( 18$)$, it is a twice continuously differentiable function and therefore, by Ito's Lemma, we can write the dynamics for $F^{k}$ as

$$
\left.d F^{k}=\mid 1 / 2 \sigma_{k}^{2} P_{k}^{2} F_{11}^{k}+F_{2}^{k}\right\rfloor d t+F_{1}^{k} d P_{k}
$$

But, $F^{k}$ satisfies (18) and hence, $1 / 2 \sigma_{k}^{2} P_{k}^{2} F_{1 !}{ }^{k}+F_{2}^{k}=\tau F^{k}-r P_{k} F_{1}^{k}-Y_{k}$. Substituting into (22), we can rewrite (22) as

$$
\left.d F^{k}=F_{1}^{k} d P_{k}+\mid r F^{k}-r P_{k} F_{1}^{k}-Y_{k}\right] d t
$$

From (21) and (23), we have that

$$
\begin{aligned}
d V-d F^{k} & =\left|r V-r P_{k} F_{l}^{k}-D_{2}-r F^{k}+r P_{k} F_{1}^{k}+Y_{k}\right| d t \\
& =d V-F^{k} \cdot d t
\end{aligned}
$$


because $D_{2}=Y_{k}$. By inspection, (24) is an ordinary differential equation with solution

$$
V(t)-F^{k}\left[P_{k}(t), t\right]=\left(V(0)-F^{k}\left[P_{k}(0), 0\right]\right) \exp [\tau t]
$$

Thus, if the initial investment in the portfolio is chosen so that $V(0)=F^{k}\left[P_{k}(0), 0\right]$, then for all $t$ and $P_{k}(t)$, we have that

$$
V(t)=F^{k}\left[P_{k}(t), t\right]
$$

To ensure that the proposed portfolio strategy is feasible, we must show that its value is always nonnegative for every possible sample path for the price $P_{k}$ and all $t, 0 \leq t \leq T_{k}$. Because $F^{k}$ is the solution to (18) and $Y_{k} \geq 0$, $F^{k} \geq 0$ for all $P_{k}$ and $t$. It follows from (26) that $V(t) \geq 0$ for all $P_{k}$ and $t$. We have therefore constructed a feasible dynamic portfolio strategy in traded asset $k$ and the riskless asset that produces the stream of cash flows $Y_{k}(t) d t$ for $0 \leq t \leq T_{k}$ and has zero residual value $\left(V\left(T_{k}\right)-0\right)$ at $T_{k}$. Because the derived strategy exactly replicates the strean of cash flows generated by source $k$, it is economically equivalent to owning the cash flows $Y_{k}(t)$ for $t \leq T_{k}$. It follows that the capitalized value of these cash flows satisfies

$$
V_{k}(t)=F^{k}\left[P_{k}(t), t\right]
$$


for $k=1 \ldots N$. Note that by inspection of $(18)-(19)$, Fk, and hence $v_{k}(t)$. does not depend on either the university's preferences or its net worth. The valuation for source $k$ is thus the same for all universities.

Armed with (27), we now turn to the optimal policy for managing endowment when the university has $N$ non-endowment sources of cash flows. To derive the optimal policy, note first that even if those non-endowment sources cannot actually be sold by the university for legal, ethical, moral hazard. or asymetric information reasons, the university can achieve the economic equivalent of a sale by following the "mirror-image" or reverse of the replicating strategy. That is, by (short-selling or) taking a $-F_{1}^{k}\left(P_{k}(t), t\right) P_{k}$ position in asset $k$ and borrowing $\left.\mid F^{k}-F_{1}^{k} P_{k}\right\rfloor$ of the riskless asset at each $t$, the portfolio will generate a positive amount of cash, $F^{k}\left[P_{k}, t\right]$, avaliable for investment in other assets at time $t$. The entire liability generated by shorting this portfolio is exactly the negative cash flows. $\left\{-Y_{k} d t\right\}$, for $t \leq T_{k}$, because $V_{k}\left(T_{k}\right)=F^{k}\left[P_{k}, T_{k}\right]=0$. But, since the university receives $Y_{k} d t$ for $t \leq T_{k}$ from source $k$, this short-portfolio liability is entirely offset. Hence, to undertake this strategy beginning at time $t$ is the economic equivalent of selling cash flow source $k$ for a price of $V_{k}(t)=F^{k}\left[P_{k}(t), t\right]$.

As discussed more generally in Merton [1990a, Sec. 14.5, especially 465-7], the optimal portfolio strategy will be as if all $N$ non-endowment assets were sold and the proceeds, together with endowment, invested in the $n$ risky traded assets and the riskless asset. This result obtains because it is feasible to sell (in the economic sense) the non-endowment assets and because 
all the economic benefits from those assets can be replicated by dynamic trading strategies in the traded assets. Hence, there is neither an economic advantage nor a disadvantage to retaining the non-endowment assets. It follows that the optimal demand for the traded risky assets is given by (13) and the demand for the riskless asset is given by $\left(1-\Sigma_{1}{ }^{n} w_{1}{ }^{*}\right) W(t)$, where from (4) and (27),

$$
W(t)=K(t)+\sum_{1}^{N} F^{k}\left[P_{k}(t), t\right] \quad .
$$

Because, however, the university has not actually sold the non-endowment assets, the optimal demands given by (13) and (28) Include both implicit and explicit holdings of the traded assets. That is, the university's ownership of non-endowment cash flow source $k$ at time $t$ is equivalent to having an additional net worth of $F^{k}\left[P_{k}(t), t\right]$ (as reflected in (28)) and to having $F_{l}{ }^{k}\left[P_{k}(t), t\right] P_{k}(t)$ invested in traded asset $k$ and $\mid F^{k}\left[P_{k}(t), t\right]$ - $\left.F_{1}{ }^{k}\left[P_{k}(t), t\right] P_{k}(t)\right]$ invested in the riskless asset. Thus, ownership of source $k$ causes implicit investments in traded asset $k$ and the riskless asset. optimal explicit investment in each traded asset is the position actually observed in the endowment portfolio and it is equal to the optimal demand given by (13) and (28) minus the implicit investment in that asset resulting from ownership of non-endowment assets. Let $D_{1}^{*}(t)$ denote the optimal explicit investment in traded asset 1 by the university at time $t$. It follows from (13) that 


$$
\begin{aligned}
D_{1}^{*}(t) & =A b_{1}+\sum_{1} H_{k} h_{k 1}-F_{1}^{1}\left[P_{1}(t), t\right] P_{1}(t), i=1, \ldots N \\
& =A b_{i}+\sum_{1} m H_{k} h_{k 1}, \quad i=N+1 \ldots, n
\end{aligned}
$$

where $W(t)$ used in the evaluation of $A$ and $H_{k}$ is given by (28). If we number the riskless asset by " $n+1$, " then explicit investment in the riskless asset can be written as

$$
\begin{aligned}
D_{n+1}^{*}(t) & =\mid 1-\left[\sum_{1}{ }^{*} w_{1}^{*}(t)\left|W(t)-\sum_{1} N\right| F^{1}\left[P_{1}(t), t\right]-F_{1}^{1}\left[P_{1}(t), t\right] P_{1}(t) \mid\right. \\
& =K(t)-\sum_{1}{ }^{n} D_{j}^{*}(t) .
\end{aligned}
$$

By inspection of (29), it is apparent that in addition to the hedging of activity costs, the existence of non-endowment sources of cash flow will cause further differences between the observed holdings of assets in the optimal endowment portfolio and the mean-variance-efficient portfolio of a "standard" investor. Similarly, from (30), the observed mix between risky assets and the riskless asset will differ from the true economic mix.

To explore further the effects of those non-endowment sources of cash flows, we solve the optimal expenditure and portfolio-selection problem for a specific utility function. $\bar{U}$. However, in preparation for that analysis, we first derive explicit formulas for the capitalized values of those sources when $Y_{k}(t)$ is given by (17). As already noted, there exists a unique solution to (18) and (19). Hence, it is sufficient to simply find a solution. As can be verified by direct substitution into (18), the value of cash flow source $k$ is given by, for $k=1, \ldots, N$, 


$$
F^{k}\left(P_{k}(t), t\right]-Y_{k}(0) \exp \left[-\phi_{k} t\right)\left(1-\exp \left(-\theta_{k}\left(T_{k}-t\right)\right]\right)\left(P_{k}(t) / P_{k}(0)\right)^{\beta_{k}} / \theta_{k}
$$

where $\beta_{k}$. $\phi_{k}$ are as defined in (17) and

$$
\theta_{k}=r+\beta_{k}\left(\alpha_{k}-r\right)-\mu_{k} .
$$

It follows from (31) that, for $k-1, \ldots N$.

$$
F_{1}{ }^{k}\left(P_{k}(t), t\right] P_{k}(t)-\beta_{k} F^{k}\left(P_{k}(t), t\right]
$$

which implies that the capitalized value of source $k$ has a constant elasticity with respect to the price of traded asset k. Equation (32) also implies that the replicating portfolio strategy is a constant-proportion or rebalancing strategy which allocates fraction $\beta_{k}$ of the portfolio to traded asset $k$ and fraction $\left(1-\beta_{k}\right)$ to the riskless asset. In the case when positive fractions are allocated to both assets $\left(1 . e \ldots\left(1-\beta_{k}\right)>0\right.$ and $\left.\beta_{k}>0\right)$. then $F^{k}$ is a strictly concave function of $P_{k}$. If $\beta_{k}>1$, then $F^{k}$ is a strictly convex function of $P_{k}$ and the replicating portfolio holds traded asset $k$ leveraged by borrowing. In the watershed case of $\beta_{k}-1$, $F^{k}$ is a linear function of $P_{k}$ and the replicating portfolio holds traded asset $k$ only.

Using (17) and (27), we can rewrite (31) to express the capitalized value of source $k$ in terms of the current cash flow it generates: namely. 


$$
V_{k}(t)=Y_{k}(t)\left(1-\exp \left[-\theta_{k}\left(T_{k}-t\right)\right]\right) / \theta_{k}, k=1, \ldots N
$$

From (17), (31a), and (32), it is a straightforward application of It0.s Lemens to show that the total expected rate of return for holding source $k$ from $t$ to $t+d t$ is given by

$$
\begin{aligned}
E_{\tau}\left[Y_{k}(t) d t+d V_{k}\right] / V_{k}(t) & =\left(\mu_{k}+\theta_{k}\right) d t \\
& =\left[r+\beta_{k}\left(\alpha_{k}-r\right)\right] d t
\end{aligned}
$$

Thus, if the rights to the cash flows $Y_{k}$ between $t$ and $T_{k}$ were sold in the market place, the expected rate of return that would be required by investors to bear the risk of these flows is $r+\beta_{k}\left(\alpha_{k}-r\right)$. Therefore, $\theta_{k}$ equals the required expected rate of return ("the capitalization rate") minus the expected rate of growth of the cash flows, $\mu_{k}$. By inspection of (33), $V_{k}(t)$ can be expressed by the classic present-value formula for assets with exponentially growing cash flows. For $\theta_{k}>0$, the perpetual $\left(T_{k}=\infty\right)$ value is $Y_{k}(t) / \theta_{k}$ and the limiting "Earnings-to-Price" ratio, $Y_{k}(t) / V_{k}(t)$, is $\theta_{k}$, a constant. Applying the closed-form solution for $F^{k}$, we can by substitution from (27) and (32) into (29) and (30) rewrite the optimal demand functions as

$$
\begin{aligned}
D_{1}^{*}(t) & =A b_{1}+\Sigma_{1} H_{k} h_{k 1}-\beta_{1} V_{1}(t), \quad i=1, \ldots N \\
& =A b_{1}+\Sigma_{1}=H_{k} h_{k 1} \quad, \quad i=N+1, \ldots n
\end{aligned}
$$

and

$$
\begin{aligned}
D_{n+1}^{*}(t) & =\left|1-\sum_{1}^{n} w_{j}^{*}(t)\right| W(t)-\Sigma_{1}^{N}\left(1-\beta_{1}\right) V_{1}(t) \\
& =K(t)-A \Sigma_{1}^{n} b_{j}-\Sigma_{1} \cdot \Sigma_{1}{ }^{n} H_{k} h_{k j}+\sum_{1}^{N} \beta_{1} V_{1}(t) .
\end{aligned}
$$


Having derived explicit formulas for the values of non-endowment assets. we turn now to the solution of the optimal portfolio and expenditure problem in the special case where the university's objective function is given by

$$
\bar{U}\left[Q_{1}, \ldots, Q_{m}, t\right]=\exp [-p t] \Sigma_{1}^{m} r_{j} \log Q_{j}
$$

with $p>0$ and $\Gamma_{g} \geq 0, j=1, \ldots, m$. Without loss of generality, we assume that $\Sigma_{1}{ }^{m} \Gamma_{1}=1$. From (8), the optimal $Q_{1}$ satisfy

$$
Q_{j}{ }^{*}(t)=\left[\Gamma_{j} C(t)\right] / S_{j}(t) \quad, j=1 \ldots . m .
$$

From (36) and (37), the indirect utility function can be written as

$$
U[C, S, t]=\exp [-p t]\left\{\log C-\Sigma_{1}-\Gamma_{j}\left[\log s_{j}-\log \left(\Gamma_{j}\right)\right]\right\}
$$

It follows from (11a) that the optimal expenditure cule is

$$
C^{*}(t)=\exp [-p t]\left(1 / J_{U}(W, S, t]\right) \quad .
$$

It is straightforward to verify by substitution into (10), (11a), and (11b) that

$$
J[W, S, t]-\frac{1}{\rho} \exp [-\rho t] \log W+I[S, t]
$$

for some function $I[S, t]$. By the verification theorem of dynamic programming. satisfaction of (10), (11a), and (11b) is sufficient to ensure that $J$ in $(40)$ is the optimum.

It follows from (40) that $J_{k H}=0$ and hence that $H_{k}=0$ in (13) and (35), $k=1, \ldots, m$. Therefore, for the log utility specified in (36), there 
are no differential hedging demands for assets to protect against unanticipated changes in the costs of university activities. The optimal allocation of the university's total net worth is thus instantaneously mean-variance efficient. Noting that $A=-J_{H} / J_{H W}=W$, we have that (35) can be written in this special case as

$$
\begin{aligned}
D_{i}^{*}(t) & =b_{1} W-\beta_{1} V_{1}(t), i-1, \ldots N \\
& =b_{1} W \quad, \quad i-N+1, \ldots, n
\end{aligned}
$$

and

$$
D^{*}{ }_{n+1}(t)=\left(1-\Sigma_{1} b_{j}\right) W-\Sigma_{1}^{N}\left(1-\beta_{i}\right) V_{1}(t)
$$

By inspection of (41), in the absence of non-endowment assets, the fraction of endowment allocated to risky asset $i$ in the university's optimal portfolio is $b_{1}, i=1, \ldots, n$ and the fraction allocated to the riskless asset is $\left(1-\Sigma_{1}{ }^{n} b_{j}\right)$, independent of the level of endowment. If $x_{i}^{*}=D_{1}^{*}(t) / K(t)$ is the optimal fraction of endowment invested in asset $i$. then from (41), the difference in fractional allocations caused by the nonendowment assets is

$$
\begin{array}{rlrl}
x_{1}{ }^{*}(t)-b_{1} & =R\left[b_{1}-\beta_{1} \lambda_{1}\right] \quad, i & =1 \ldots N \\
& =R b_{i} & , i & =N+1, \ldots n
\end{array}
$$

and

$$
x_{n+1}^{*}(t)-\left(1-\Sigma_{1}^{n} b_{j}\right)=-R\left[\Sigma_{1}^{n} b_{k}-\Sigma_{1}^{N} \beta_{k} \lambda_{k}\right]
$$

where $\lambda_{k}=V_{k}(t) / \Sigma_{1} V_{1}(t)$ is the fraction of the capitalized value of the 
university's total non-endowment assets contributed by cash flow source $k$ at time $t, k=1, \ldots, N$ and $R=\Sigma_{1}{ }^{N} V_{1}(t) / K(t)$ is the ratio of the values of the university's non-endowment assets to its endowment assets at time $t$. The differences in (42) are the result of two effects: (i) the "wealth" effect caused by the difference between the net worth and the endowment of the university and (ii) the "substitution" effect caused by the substitution of non-endowment asset holdings for traded asset holdings. Suppose, for concreteness, that the expected returns, variances, and covariances are such that a positive amount of each traded risky asset is held in mean-variance-efficient portfolios. Then, $b_{1}>0, i=1, \ldots, n$. It follows that the impact of the wealth effect in (42), $\left\{R b_{1}\right\}$, is unambiguous: it causes a larger fraction of the optimal endowment portfolio to be allocated to each risky asset and therefore, a smaller percentage allocation to the riskless asset. Because $\beta_{1} \geq 0$ and $\lambda_{1}>0,1=1, \ldots, N$, we have that the impact of the substitution effect in (42), $\left\{R \beta_{1} \lambda_{1}\right\}$, is also unambiguous: for those traded assetg 1...., for which the non-endowment assets are substitutes, the fractional allocation is smaller; for the traded assets $N+1, \ldots, n$, the fractional allocation is unchanged; and the allocation to the riskless asset thus increases.

Because the wealth and substitution effects are in opposite directions for $b_{k}>0$, whether the optimal endowment portfolio allocates an incrementally larger or smaller fraction to traded asset $k$ depends on whether $b_{k}>$ $\beta_{k} \lambda_{k}$ or $b_{k}<\beta_{k} \lambda_{k} . \beta_{k} \lambda_{k}$ is the fraction of the total increment to net worth (from non-endowment assets) that is implicitly invested in asset $k$ as 
the result of owning cash flow source $k$. If that fraction exceeds the optimal one for total wealth, $b_{k}$. then the optimal endowment portfolio will hold less than the mean-variance-efficient allocation. Indeed, if $\lambda_{k}>(1+$ R) $b_{k} /\left(R \beta_{k}\right)$, then $x_{k}{ }^{*}(t)<0$ and the university would optimally short-sell traded asset $k$ in its portfolio. This is more likely to occur when $R$ is large (i.e.. non-endowment assets are a large part of university net worth) and $\lambda_{k}$ is large (i.e., cash flow source $k$ is a large part of the value of non-endowment assets).

The implications of (42) for optimal endowment are intuitive. If. for example, a significant amount of gift-giving to a particular university depends on the performance of the general stock market, then in effect that university has a "shadow" investment in that market. Hence, all else the same, it should hold a smaller portion of its endowment in stocks than another university with smaller amounts of such market-sensitive gift-giving. The targeting can be more specific: If a school specializes in science and engineering and if an important part of gifts comes from entrepreneur alums: then the endowment should underweight (or even eliminate) investment in venture capital and hi-tech companies. Indeed, if a single donor is expected to give a large block of a particular stock, then the optimal explicit holding of that stock in the endowment may be negative (although such short-sales might offend some donors). Much the same story applies to concentrations in other assets, including real estate. The same analysis also follows where grants from firms or the government are likely to be strongly correlated with the financial performance of stocks in the related industries. 
It is perhaps a bit of a paradox that the university should under-invest the endowment in those sectors of assets for which it has special expertise (e.g., science and technology). But, the seeming paradox is resolved once the principle of diversification is invoked. However, the underweighting in those assets for diversification reasons can be offset by sufficiently strong demands to hedge against costs. For example, suppose that a specialized institute of biology believes that the cost of keeping the faculty will rise by considerably more than tuition in the event that there is a strong demand for such scientists outside academe. Then it may be optimal to invest a portion of its endowment in bio-tech stocks to hedge this cost even though those stocks' returns are highly correlated with alum gifts and industry grants.

The analysis leading to (29) and (30) requires that there exist traded securities which are instantaneously perfectly correlated with the changes in $Y_{1}, \ldots, Y_{N}$. If this assumption is relaxed, then the capitalized values of those non-endowment cash flow sources will no longer be independent of the university's preferences and endowment. However, the impact on endowment investments will be qualitatively similar. This more general case of nonreplicable assets can be analyzed along the lines of Svensson (1988).

We can use our model to examine the impact of non-endowment cash flow sources on optimal expenditure policy. From (39) and (40), we have that the optimal expenditure rule is the constant-proportion-of-net-worth policy

$$
C^{*}(t)=p H(t)
$$


However, current expenditure from endowment will not follow a constant proportion strategy. Optimal expenditure from endownent at time $t$ is $\left[C^{*}(t)-\Sigma_{1}^{N} Y_{k}(t)\right] d t$, which can be either positive or negative (implying net saving from non-endowment cash flow sources). If $s^{*}(t)$ denotes the optimal expenditure rate as a fraction of endowment $\left(=\left[C^{*}(t)-\Sigma_{1}^{N} Y_{k}(t)\right] / K(t)\right)$, then from (4) and (43)

$$
s^{*}(t)=p+R(t)[p-y(t)]
$$

where $R(t)$ is as defined in $(42)$ and $y(t)=\left[\Sigma_{1}{ }^{N} Y_{k}(t)\right] /\left[\Sigma_{1}{ }^{N} V_{k}(t)\right\}$ is the current yield on the capitalized value of the non-endowment sources of cash flow. In the special case of (33) where the cash flows are all perpetuities (i.e., $T_{k}=\infty$ and $\left.\theta_{k}>0, k=1, \ldots, N\right), V_{k}(t)=Y_{k}(t) / \theta_{k}$, and the current yield on source $k$ is constant and equal to $\theta_{k}$. In that case, $y(t)=$ $\Sigma_{1}^{N} \lambda_{k} \theta_{k}$, the value-weighted current yield. From (31a), $\theta_{k}$ will tend to be smaller for assets with higher expected growth rates of cash flow, $\left\{\mu_{k}\right\}$. If on average, the current yield on non-endowment assets is less than $\rho$. then the current spending rate out of endowment will exceed $\rho$. If the current yield is high so that $y(t)>p$, then $s^{*}(t)<p$. Indeed, if $y(t)>p(1+$ $R) / R$, then $s^{*}(t)<0$ and optimal total expenditure is less than current cash flow generated by non-endowment sources. Because both $R(t)$ and $\lambda_{k}(t)$ change over time. we have from (44) that the optimal current expenditure rate from endowment is not a constant, even when expected returns on assets, the interest rate. and the expected rate of growth of non-endowment cash flows are constants. 
We can also analyze the dynamics of the mix of the university's net worth between endowment and non-endowment assets. If $\alpha=r+\Sigma_{1} b_{1}\left(\alpha_{1}-r\right)$ denotes the instantaneous expected rate of return on the growth-optimum, meanvariance-efficient portfolio, then as shown in Merton (1990a, 169-71), the resulting distribution for that portfolio is log-normal with instantaneous expected return $\alpha(>r)$ and instantaneous variance rate equal to $(\alpha-r)$. It follows from (6), (41), and (43) that the dynamics for the university's net worth are such that $W(t) / W(0)$ is log-normally distributed with

$$
\begin{aligned}
& E_{0}[W(t)]=W(0) \exp [(\alpha-p) t] \\
& E_{0}(\log [W(t) / W(0)])=[(\alpha+r) / 2-p] t \\
& \operatorname{Var}(\log [W(t) / W(0)])=(\alpha-r) t .
\end{aligned}
$$

If $X_{k}(t)=V_{k}(t) / W(t)$ denotes the fraction of net worth represented by nonendowment cash flow source $k$, then because $v_{k}$ and $w$ are each log-normally distributed, $x_{k}(t)$ is log-normally distributed and from (33) and (45).

$$
\begin{aligned}
& E_{0}\left[X_{k}(t)\right]=X_{k}(0) \exp \left[\left(p-\theta_{k}\right) t\right] \\
& E_{0}\left(\log \left[X_{k}(t) / X_{k}(0)\right]\right)=\left[\mu_{k}+p-\left(\alpha+r+\delta_{k}{ }^{2}\right) / 2\right] t \\
& \operatorname{Var}\left(\log \left[X_{k}(t) / X_{k}(0)\right]\right)-\left[\delta_{k}{ }^{2}+\alpha+r-2\left(\mu_{k}+\theta_{k}\right)\right] t
\end{aligned}
$$

for $k=1, \ldots, N$.

From (46), the fraction of total net worth represented by all sources of non-endowment cash flow, $X(t)=\Sigma_{1}{ }^{N} X_{k}(t)=R(t) /[1+R(t)]$, is expected to grow or decline depending on whether $p>\theta_{a 1}$ or $p<\theta_{\text {min }}$ where $\theta_{\min }=\min \left[\theta_{k}\right], k=1, \ldots, N$. In effect, a university with either a high rate 
of time preference or at least one (perpetual) high-growth non-endowment asset (i.e.. with $p>\theta_{\text {an }}$ ) is expected to "eat" its endowment. Indeed, it may even go to a "negative" endowment by borrowing against the future cash flows of its non-endowment assets. Whether this expected growth in $X(t)$ is the result of declining expected net worth or rising asset values can be determined from (45). Because $\alpha>r$, if $p \leq r$, then both the arithmetic and geometric expected rates of growth for net worth are positive. For $p<\theta_{\text {ain }}$. it follows that $E_{0}[X(t)]-0$ as $t-\infty$. Hence, in the long run of this case, endowment is expected to become the dominant component of the university's net worth. Of course, these "razor's edge" results on growth or decline reflect the perpetual, constant-growth assumptions embedded in nonendowment cash flow behavior. However, this special case does capture the essential elements affecting optimal portfolio allocation and expenditure policies. [cf. Tobin (1974).] 


\section{Summary and Conclusions}

As indicated at the outset, a common approach to the management of endowment is to treat it as if it were the only asset of the university. A consequence of this approach is that optimal portfolio strategies are focused exclusively on providing an efficient tradeoff between risk and expected return. The most common practice is to measure portfolio risk by the variance or standard deviation of its return. Because the returns on all mean-variance efficient portfolios are perfectly correlated, a further consequence of exclusive focus on efficiency is that the optimal endowment portfolios of different universities should have quite similar risky components, at least as measured by the correlations of their returns.

But, as we all know, universities have other assets, both tangible and intangible, many of which are important sources of cash flow. As noted in Section 2, examples of such sources include gifts, bequests, university business income, and public and private-sector grants. The analysis in the preceding sections shows that taking account of those assets can cause the composition of the optimal endowment portfolio to deviate significantly from mean-variance efficiency. It follows that two universities with similar objectives and endowments of the same size can nevertheless have very different optimal endowment portfollos if their non-endowment sources of cash flow are different. The effect on the composition of the optimal endownent portfolios induced by differences in the size of non-endowment assets can be decomposed into two parts: the wealth effect and the substitution effect.

To illustrate the wealth effect, consider two universities with identi- 
cal preference functions and the same size endowments, but one has nonendowment assets and the other does not. If, as is perhaps reasonable to suppose, the preference function common to each, exhibits decreasing absolute risk aversion, then the university with the non-endowment assets (and hence larger net worth) will prefer to have a larger total investment in risky assets. Such behavior is consistent with the belief that wealthier universities can "afford" to take larger risks with their investments. Thus, if the average risk of the non-endowment assets is the same as the risk of the endowment-only university's portfolio, then the university with those assets will optimally invest more of its endowment in risky assets.

The substitution effect on the endowment portfolio is caused by the substitution of non-endowment asset holdings for endowment asset holdings. To illustrate, consider the two universities of the previous paragraph, but now increase the size of the endowment of the endowment-only university so that net worth or wealth is the same for both. The optimal deployment of total net worth is identical for each university. However, those assets held as nonendowment assets will not appear in the endowment portfolio. Thus, if the composition of the two endowment portfolios are compared, they will differ in both scale and fractional allocations among the various assets.

To illustrate the substitution effect more concretely, we draw on some examples analyzed in section 3. Consider a university that on a regular basis receives donations from alums. Clearly, the cash flows from future contributions are an asset of the university, albeit an intangible one. Suppose that the actual amount of gift-giving is known to be quite sensitive to the 
performance of the general stock market. That is, when the market does well, gifts are high and when it does poorly, gifts are low. Through this giftgiving process, the university thus has a "shadow" investment in the stock market. Hence, all else the same, it should hold a smaller portion of its endowment in stocks than another university with smaller amounts of such market-sensitive gift-giving .

As discussed in the previous section, the same principle applies to more specific asset classes. If an important part of gifts to a school that specializes in science and engineering comes from entrepreneur alums, then the school de facto has a large investment in venture capital and hi-tech companies and it should therefore invest less of its endownent funds in those areas. That the school should optimally invest less of its endowment in the science and technology areas where its faculty and students have special expertise may seem a bit paradoxical. But, the paradox is resolved by the principle of diversification once the endowment is recognized as representing only a part of the assets of the university. The same analysis and conclusion applies if we were to change the example by substituting either government and corporate grants for donations and gift-giving as the sources of cash flows or alum wealth concentrations in other assets such as real estate for concentrations in shares of stock. As also shown in the preceding section, the nature and size of a university's non-endowment assets should significantly influence optimal policy for expenditure of endowment. Hence, neglecting those other assets will bias the optimal expenditure policy. In addition to taking account of non-endowment assets, our analysis 
differs from the norm because it takes account of the uncertainty surrounding the costs of the various activities such as education, research, and knowledge storage that define the purpose of the university. As discussed in section 2 . the breakdown of activities can be considerably more refined. For instance, one activity could be the education of a full-tuition-paying undergraduate and a second could be the education of an undergraduate who receives financial aid. The unit (net) cost of the former is the unit cost of providing the education less the tuition received and the unit cost of the latter is this cost plus the financial aid given. As shown in section 2, an important function of endowment investments is to hedge against unanticipated changes in the costs of university activities.

As an example, consider the decision as to how much (if any) of the university's endowment to invest in local residential real estate. From a standard mean-variance-efficiency analysis, it is unlikely that any material portion of the endownent should be invested in this asset class. However. consider the cost structure faced by the university for providing teaching and research. Perhaps the single largest component is faculty salaries. Universities of the same type and quality compete for faculty from the same pools. To be competitive, they must offer a similar standard of living. Probably the largest part of the differences among universities in the cost of providing this same standard of living is local housing costs. By investing in local residential housing, the university hedges itself against this future cost uncertainty by acquiring an asset whose value is higher than expected when the differential cost of faculty salaries is higher than expected. This same 
asset may also provide a hedge against unanticipated higher costs of offcampus housing for students which would in turn require more financial aid if the university is to compete for the best students. Note: This prescription of targeted investment in very specific real estate assets to hedge against an unanticipated rise in a particular university's costs of faculty salaries and student aid should not be confused with the often-stated (but empirically questionable) assertion that investments in real estate generally are a good hedge against inflation. See Bodie (1976;1982) for empirical analysis of the optimal assets for hedging against general inflation.

Similar arguments could be used to justify targeted investment of endowment in various commodities such as oil as hedges against unanticipated changes in energy costs. Uncertainty about those costs is especially significant for universities located in extreme climates and for universities with major laboratories and medical facilities that consume large quantities of energy.

As discussed at the end of Section 2, the hedging role for endowment derived here is formally valid as long as there are traded securities with returns that have non-zero correlations with unanticipated changes in the activity costs. However, the practical significance for this role turns on the magnitude of the correlations. As illustrated in Bodie's (1976;1982) work on hedging against inflation, it is often difficult to construct portfolios (using only standard types of traded securities) that are highly correlated with changes in the prices of specific goods and services. Nevertheless, the enormous strides in financial engineering over the last decade have greatly 
expanded the opportunities for custom financial contracting at reasonable costs. As we move into the twenty-first century, it will become increasingly more comon for the financial services industry to offer to its customers private contracts or securities that allow efficient hedging when the return properties of publicly-traded securities are inadequate. That is, implementation of the strategies prescribed in Sections 2 and 3 will become increasingly more practical for universities and other endownent institutions. See Merton (1990a. Ch. 14:1990c, 264-9) for a prospective view on Einancial innovation and the development of custom financial contracting.

There are of course a variety of issues involving endownent management that have not been addressed but could be within the context of our model. One such issue is the decision whether to invest endowment in specific-purpose real assets such as dormitories and laboratories instead of financial (or general-purpose physical) assets. The returns on those real assets are likely to be strongly correlated with the costs of particular university activities and thereby the assets form a good hedge against unexpected rises in those costs. However, because the real asset investments are specialized and largely irreversible, shifting the asset mix toward such investments reduces flexibility for the university. That is, with financial assets, the university has more options as to what it can do in the future. In another paper, I plan to analyze this choice problem more formally by using contingent-claims analysis to value the tradeoff between greater flexibility in selecting future activities and lower costs in producing a given set of activities. Another issue not explicitly examined is the impact of long-term. fixed 
liabilities such as faculty tenure contracts on the management of endowment. As noted early in Section 2, our model using contingent claims analysis (CCA) can handle this extension. See McDonald (1974) and Merton (1985) for CCA-type models for valuing tenure and other wage guarantee contracts.

The formal analysis here assumes that endowment is fungible for other assets and that neither spending nor investment policy are restricted. Such restrictions on endowment could be incorporated using the same Kuhn-Tucker type analysis used in section 2 to take account of the constraint that total expenditure at each point in time is nonnegative. The magnitudes of the KuhnTucker multipliers at the optimum would provide a quantitative assessment of the cost of each such restriction. However, including those restrictions is not likely to materially change the basic insights about hedging and diversification derived in the unrestricted case. The model can also be integrated into a broader one for overall university financial planning. Such integration would permit the evaluation of other non-endowment financial policies such as whether the university should sell forward contracts for tuition. In summary, we have explored two classes of reasons why optimal endowment investment policy and expenditure policy can vary significantly among universities. The analysis suggests that trustees and others who judge the prudence and performance of policies by comparisons across institutions should take account of differences in both the mix of activities of the institutions and the capitalized values of their non-endowment sources of cash flows. 


\section{REFERENCES}

Bergman, Yakov (1985), "Time Preference and Capital Asset Pricing Models," Journal of Financial Economics. 14(March):145-59.

Black, Fischer (1976), "The Investment Policy Spectrum: Individuals, Endowment Funds and Pension Funds." Financial Analysts Journal, 32 (JanuaryFebruary):23-31.

Bodie, Zvi (1976). "Common Stocks as a Hedge Against Inflation," Journal of Finance, 31 (May) $: 459-70$.

(1982), "Investment Strategy in an Inflationary Environment," in Benjamin Friedman, ed. The Changing Roles of Debt and Equity in Pinancing o.S. Capital Pormation, Chicago, IL: University of Chicago Press: 47-64.

Breeden, Douglas T. (1979), "An Intertemporal Asset Pricing Model with Stochastic Consumption and Investment Opportunities," Journal of Financial Economics, 7(September):265-96.

Brinkman, Paul T. (1981), "Factors Affecting Instructional Costs at Major Research Universities," Journal of Higher Education, 52(May-June):265-79.

(1990), Higher Education Cost Functions, in Hoenack and Collins, eds. (1990):107-28.

Brovender, Shlomo (1974), "On the Economics of a University: Toward the Determination of Marginal Cost of Teaching Services." Journal of Political Economy, 82(May-June): 657-64.

Constantinides, George (1989), "Theory of Valuation: Overview and Recent Developments" in Sudipto Bhattacharya and George Constantinides, eds.. Theory of Valuation: Frontiers of Hodern Finance Theory, Volume 1, Totowa, NJ: Rowman \& Littlefield:1-23.

(1990). "Habit Formation: A Resolution of the Equity Premium Puzzle," Journal of Political Economy, 98(June):519-43.

Detemple, Jerome B. and Fernando Zapatero (1989), "Optimal ConsumptionPortfolio Policies with Habit Formation." Working Paper, Graduate School of Business. Columbia University. New York, NY.

Duffie. Darrell and Larry Epstein (1989), "Stochastic Differential Utility and Asset Pricing," unpublished manuscript. Graduate School of Business, Stanford University, Stanford, CA (September).

Eisner, Robert. (1974), "Endowment Income, Capital Gains and Inflation Accounting: Discussion," American Economic Review, 64(May):438-41. 
Ennis, Richard and J. Peter Williamson (1976), "Spending Policy for Educational Endowments," Research and Publication Project, The Common Fund (January).

Fama, Eugene and Michael C. Jensen (1985), "Organizational Forms and Investment Decisions," Journal of Finsncial Economics, 14(March):101-19.

Fischer, Stanley (1975). "The Demand for Index Bonds," Journal of Political Economy, 83(June):509-34.

Ford Foundation Advisory Committee on Endownent Management (1969). Managing Educational Endowments: Report to the Ford Foundation, Ford Foundation, New York, NY.

Grinold, Richard, David Hopkins, and William Massy (1978), "A Model for LongRange University Budget Planning Under Uncertainty." Bell Journal of Economics, 9 (Autumn) :396-420.

Grossman, Sanford and Guy Laroque (1990). "Asset Pricing and Optimal Portfolio Choice in the Presence of Illiquid Consumption Goods, "Econometrica, 58 ( January) $: 25-52$.

Hansmann, Henry (1990), "Why Do Universities Have Endowments?" Journal of Legal Studies, 19(January):3-42.

Hindy, Ayman and Chi-fu Huang (1989), "On Intertemporal Preferences With a Continuous Time Dimension II: The Case of Uncertainty," Working Paper No. 2105-89(March), A.P. Sloan School of Management, MIT, Cambridge, Massachusetts.

Hoenack, Stephen and Eileen Collins, eds. (1990), The Economics of American Universities, Albany: State University of New York Press.

Litvack, James, Burton Malkiel and Richard Quandt (1974), "A Plan for the Definition of Endowment Income," American Economic Review, 64(May):433-42.

McDonald, John (1974), "Faculty Tenure as a Put Option: An Economic Interpretation," Social Science Quarterly, 55(September):362-71.

Merton, Robert C. (1977), "A Reexamination of the Capital Asset Pricing Model." in Irwin Friend and James Bicksler, eds., Risk and Return in Finance, Volume 1, Cambridge, MA: Ballinger Publishing:141-60.

(1985), "Comment: Insurance Aspects of Pensions," in David A. Wise, ed., Pensions, Labor and Individual Choice, Chicago, IL: University of Chicago Press:343-56.

(1990a), Continuous-Time Finance, Oxford: Basil Blackwell. 
(1990b), "Capital Market Theory and the Pricing of Financial Securities," in Benjamin Friedman and Frank Hahn, eds. Handbook of Monetary Economics, Ansterdam: North-Holland Publishing:498-581.

(1990c). "The Financial System and Economic Performance." Journal of Financial Services Research, 4(December):263-300.

Nichols. Donald (1974), "The Investment Income Formula of the American Economic Association." American Economic Review, 64(May):420-26.

Nordhaus, William (1989), "Risk Analysis in Economics: An Application to University Finances," unpublished paper (May). Cowles Foundation, Yale University, New Haven, CT.

Snyder. Thomas (1988), "Recent Trends in Higher Education Finance: $1976-77$ to 1985-86." in Thomas Snyder and Eva Galambos, eds., Higher Education Administrative Costs: Continuing the Study, Washington, DC: Office of Educational Research and Improvement. Department of Education:3-23.

Sundaresan, Suresh (1989). "Intertemporally Dependent Preferences and the Volatility of Consumption and Wealth, "Review of Financial Studies, 2:7389 .

Svensson, Lars (2988). "Portfolio Choice and Asset Pricing With Nontraded Assets," Working Paper No. 2774, National Bureau of Economic Research. Cambridge, MA (November).

(1989). Portfolio Choice With Non-Expected Utility in

Continuous Time," Economic Letters, 39(October):313-17.

Tobin, James (1974), "What is Permanent Endowment Income?" American Economic Review, 64 (May):427-32. 
</ref_section> 